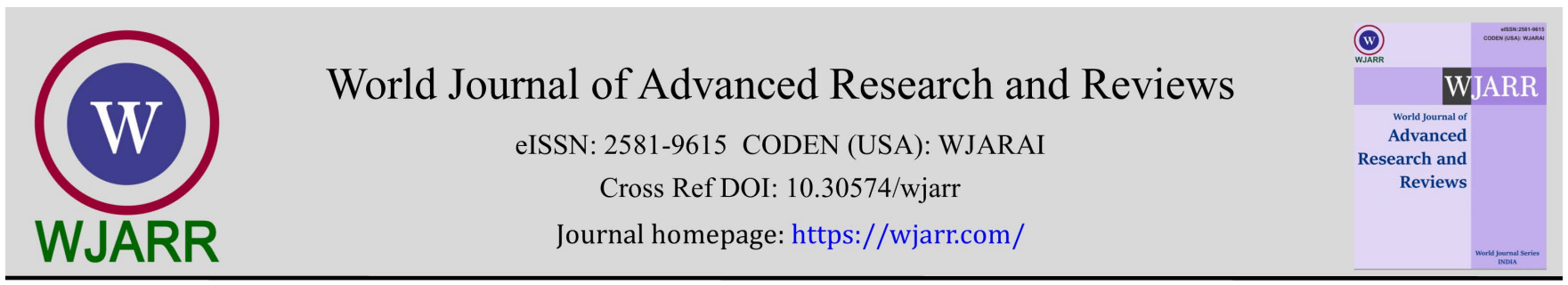

(RESEARCH ARTICLE)

\title{
Effect of different organic growing mediums and application of biofertilizer in organic seedling production
}

\author{
Omeed Jamal Ahmed Haska ${ }^{1}$, Selçuk Söylemez ${ }^{2, *}$ and Taha Zubair Sarhan ${ }^{3}$ \\ ${ }^{1}$ Directorate of Research Center, Minister of Agriculture, Duhok-Iraq. \\ ${ }^{2}$ Harran University, Agriculture Faculty, Department of Horticulture, Şanliurfa-Turkey. \\ ${ }^{3}$ Duhok Polytechnic University, Zakho Technical institute, Department of Protected Cultivation, Zakho-IRAQ.
}

World Journal of Advanced Research and Reviews, 2022, 13(02), 252-263

Publication history: Received on 25 December 2021; revised on 08 February 2022; accepted on 10 February 2022

Article DOI: https://doi.org/10.30574/wjarr.2022.13.2.0747

\begin{abstract}
Current study was done for evaluation the effect of different growing media and biofertilizer application on seedling quality. The research was conducted on tomato, pepper, and eggplant seedlings in a greenhouse of General Directorate of Agriculture, Zakho city, Duhok Governorate, Northern Iraq during the spring season of 2021. In the experiment, the 6 growing medias (M1: Soil + sand + sheep manure (1:1:1), M2: Compost, M3: Peat moss, M4: Soil + chicken manure (1:1), M5: Soil + sheep manure (1:1), and M6: Peat moss + compost (1:1)) and 2 doses (0 and $\left.10 \mathrm{~g} \mathrm{~L}^{-1}\right)$ biofertilizer applications were tried. The data analysis revealed that the growing mediums and biofertilizer applications significantly affected seed germination rate, the seed germination speed and vegetative growth parameters such as number of leaves, stem diameter, chlorophyll index, shoot fresh weight and fresh weight of roots. Moreover, the leaf mineral content of $\mathrm{N}$, $\mathrm{P}$, and $\mathrm{K}$ was importantly affected by the growing medium and the biofertilizer. The results showed that biofertilizer application can improve the seedling quality in production of organic seedling. The peat moss medium produced the best seedling quality compared to other mediums.
\end{abstract}

Keywords: Seedlings; Growing media; Bio health product; Organic production

\section{Introduction}

Organic farming is a system which does not rely on the usage of inorganic fertilizers for crop production and instead use the natural inputs at each stage of crop growth from seeding till harvesting. Organic agriculture became under spotlights as a result of green revolution that has been started in the second half of the $20^{\text {th }}$ century in an attempt to reduce the health adverse effect and ecological imbalance caused by intensive use of hazardous chemicals [1,2,3,4].

Tomato (Solanum lycopersicum), pepper (Capsicum annuum L.), and eggplant (Solanum melongena) are three important members of Solanaceae family that are well-know and widely planted worldwide. They are very valuable from nutritional and medicinal aspect and therefore, widely consumed for such purpose.

Seedling production is considered as the most critical step in the crop cycle for obtaining a high quality vegetable product [5]. The most prominent indicators for seedling quality encompass better root development, perfect shoot to root ratio with adequate amount of carbohydrate content and freeing from nutrients shortage and pests and diseases [6].

\footnotetext{
* Corresponding author: Selçuk Söylemez

Harran University, Agriculture Faculty, Department of Horticulture, Şanlıurfa-Turkey. 
The growing medium is that solid material which replaces normal soil substrate used for growing a huge number of horticultural crops and permits the root proliferation in a regular status through taking up water and nutrients. The growing medium may be prepared from organic inputs like peat moss, compost, organic manures, tree barks, coconut, sawdust or from inorganic inputs, including clay, perlite, vermiculite, mineral wool, volcanic tuff, etc. these materials can be utilized solely or in combination to make suitable mixtures for raising seedlings of certain plants depending upon their physical and chemical features that are directly correlated with agronomical performance $[7,8,9,10]$. Melo et al. [11] reported that the growing medium composed of peat moss caused a remarkable increase in the rate of seed germination and seedling emergence of the tomato crop. Unal [12] investigated the influence of different growing medium on growth and quality of pepper and tomato and showed that the best vegetative growth and quality of seedling of both crops was owed to the peat growing medium compared to control and other growing mediums. Olaria et al. [13] that growing tomato, pepper, and eggplant in an organic growing medium significantly improved the vegetative traits of the three crops. Tuzel et al. [14] observed that the growing medium composed of a mixture of local peat and vermicompost importantly increased root growth components of tomato seedlings surpassing different growing mediums. Awad [15] revealed that the compost-based medium significantly elevated growth and mineral content (N, P, and $\mathrm{K}$ ) of organic tomato seedlings. El-Sayed et al. [16] proved in a field trial that raising strawberry plants in perlite: peat-moss $(1: 1 \mathrm{v} / \mathrm{v})$ resulted in an enhancement in the $\mathrm{N}, \mathrm{P}$, and $\mathrm{K}$ content of the leaves of the crop in comparison with other mediums.

Biofertilizer are organic microbial inoculants which contain living cells of specific strains of microorganisms earned from plant roots and rhizosphere that are beneficial for plant growth and development. When biofertilizers are inoculated to plant roots or seeds, they are active in improving outgrowth and productivity of the crop up to $10-40 \%$ [17]. These microbial inoculants locate at the rhizosphere and within the plants and induce plant growth, soil fertility and crop yield via providing nourishing elements to the soil and reducing plant pests and diseases as well as enhancing root growth and breaking down the organic material leading to better outstanding of seedlings with shorter flowering period $[18,19]$. Nurlila et al. [20] found that treating tomato plants with bacteria exhibited efficacy in increasing the vegetative growth of the crop in term of leaf number per plant, stem diameter, plant height, relative growth rate and root ratio as compared to control. Salih Mahdi and Hussein [21] reported that inoculating eggplant seedlings with Bio health product significantly ameliorated vegetative growth of the plant in comparison with control. Rueda et al. [22] searched the impact of two bio-fertilizers; Azotobacter spp. and Azospirillum spp. on growth and yield of hydroponically grown strawberry (Fragaria vesca) and they recorded the highest values of the root fresh and dry weight of the crop due to the application of both fertilizers. Abou-El-Hassan and El-Shinawy [23] demonstrated that the 100 and $150 \%$ compost + humic acid + effective microorganisms (EM) and 150\% compost + EM was effective in giving the premium content of N, P, K and Ca in leaves of cabbage crop. Therefore, the aim of this pot experiment is to produce healthy vigor vegetable seedlings with lower costs and higher quality and free from toxic chemical residues and resistance to abiotic stress as well as maintaining the environment from pollution.

\section{Material and methods}

\subsection{Material}

The pot experiment was carried out in a plastic house of $\left(500 \mathrm{~m}^{2}\right)$ at the nursery of General Directorate of Agriculture, Zakho city, Duhok Governorate, Northern of Iraq during the spring season of 2021. Seeds of vegetable belonging to the Solanaceae family, namely tomato (Marglobe, Pagano Costantino \& F.lli Srl), pepper (Sigaretta Di Bergamo, Pagano Costantino \& F.lli Srl), and eggplant (Violetta Lunga Di Romagna 3, Pagano Costantino \& F.lli Srl) were sowed in plate pods on February 24th 2021.

Table 1 Chemical analysis of different used growing mediums

\begin{tabular}{|l|c|c|c|c|}
\hline \multicolumn{1}{|c|}{ Types of growing medium } & N-available & P-available & $\mathbf{p H}$ & EC \\
\hline Soil + Sand + Sheep manure1:1:1 & 0.66 & 13.13 & 7.34 & 1.86 \\
\hline Compost & 0.45 & 5.96 & 7.21 & 1.74 \\
\hline Peat moss & 0.84 & 11.01 & 7.18 & 1.03 \\
\hline Soil + Chicken manure 1:1 & 1.35 & 12.12 & 7.96 & 2.46 \\
\hline Soil + Sheep manure 1:1 & 1.14 & 5.95 & 7.91 & 1.25 \\
\hline Peat moss + Compost 1:1 & 0.45 & 6.57 & 8.53 & 1.18 \\
\hline
\end{tabular}


Transplants were cultivated in pots of the same volume using six different mediums. The study consisted of growing mediums mixes (M1: Soil + sand + sheep manure (1:1:1), M2: Compost, M3: Peat moss, M4: Soil + chicken manure (1:1), M5: Soil + sheep manure (1:1), and M6: Peat moss + compost (1:1)) and root inoculation with $10 \mathrm{~g} \mathrm{~L}^{-1}$ of biofertilizer (Bio Health WSG) and their interactions. Some properties of mediums and the content of biofertilizer were given in Table 1 and Table 2, respectively.

Table 2 Composition (typical values based on dry matter) of biofertilizer (This table was taken from the company's website)

\begin{tabular}{|l|c|}
\hline Algae Extract (Ascophyllum nodosum) & $\mathbf{1 0} \%$ \\
\hline Trichoderma harzianum & $10^{6} \mathrm{cfu} / \mathrm{g}$ \\
\hline Bacillus subtilis & $10^{7} \mathrm{cfu} / \mathrm{g}$ \\
\hline${\text { Total Humic Acids }{ }^{1 / 2}}^{\prime}$ & $66-68 \%$ \\
\hline Humic Acid $^{1}$ & $61-62 \%$ \\
\hline Fulvic Acid ${ }^{1}$ & $5-6 \%$ \\
\hline Potassium - Humates & $75 \%$ \\
\hline Potassium (K $\left.{ }_{2} \mathrm{O}\right)$ & $10-12 \%$ \\
\hline Dry Matter & $83-85 \%$ \\
\hline Organic Substance & $68-70 \%$ \\
\hline pH - value & $9.5-10.5$ \\
\hline Bulk Density & $0.55-0.65 \mathrm{~kg} / \mathrm{L}$ \\
\hline
\end{tabular}

\subsection{Methods}

The biofertilizer (Bio Health WSG) solution was prepared by mixing 10 grams with a liter of water, then the mixture was shaken well for optimum dissolution. The first inoculation was performed on March $30^{\text {th }} 2021$ which was for tomato and eggplant. The second inoculation was implemented on April 7th 2021 for tomato, pepper and eggplant and the last one was done on April 14 2021 which was done only for pepper seedlings. The following parameters were measured in the trial:

\subsubsection{Germination rate (\%)}

For each treatment 30 seeds were sowed and each treatment was repeated in 3 replicates the germination percentage was calculated according to the equation below:

$$
\text { Germination percentage }=\frac{\text { Number of germinated seeds }}{\text { Total number of sowed seed }} x 100
$$

\subsubsection{Vegetative growth parameters}

The number of leaves per seedling was counted using four plants in each experimental unit for all of the three crops. The leaf chlorophyll index (\%) was measured using a chlorophyll meter SPAD device. The stem diameter (mm) was measured at the stem's bottom using digital caliper. The fresh weight of shoots (g) was determined by sensitive electronic balance after the roots detached from the stem. The fresh weight of roots was measured in $g$ by weighing them using the sensitive electronic balance.

\subsubsection{Mineral content in leaves}

The leaf nitrogen percentage was measured according to the modified method of Kjeldahl and the process was done by employing of the Microkjeldahl equipment [24] that cited by Black [25]. The leaf phosphorus percentage was determined depending upon the colorimetric methods and the spectrophotometer instrument was employed [26]. The leaf potassium percentage was analyzed based on flame method by use of the flame photometer instrument [27, 28]. 


\subsection{Statistical analysis}

The factorial Randomized Complete Block Design (RCBD) was used for treatment arrangement and the trial included 36 treatments $(2 \times 6 \times 3=36)$, each treatment was replicated three times and each treatment was represented by 30 plants. The data were analysed using (SAS, 2010) program and Duncan multiple range test at $5 \%$ was used.

\section{Results}

\subsection{Germination rate $(\%)$}

The data listed in the Table 3 are displayed the effects of various growing medium on germination rate of tomato, pepper and eggplant crops. The effect of mediums on germination rate was significant in all species. The highest seed germination rate $(100.00 \%)$ recorded for seeds sowed in mediums contained the substrates M3 (peat moss) and the M6 (peat moss + compost 1:1) for tomato. The highest germination rate in pepper and eggplant was seen in seeds sown in M3 medium and were determined as $85.53 \%$ and $87.77 \%$, respectively. The lowest germination rate was recorded in M1 for tomato and in M4 for pepper and eggplant.

Table 3 Effect of different growing mediums and biofertilizer on germination rate (\%) of tomato, pepper, and eggplant seedlings

\begin{tabular}{|l|c|c|c|c|c|c|}
\hline \multirow{2}{*}{ Species } & \multicolumn{7}{|c|}{ Media } \\
\cline { 2 - 7 } & M1 & M2 & M3 & M4 & M5 & M6 \\
\hline Tomato & $68.87 \mathrm{c}$ & $91.07 \mathrm{ab}$ & $100.00 \mathrm{a}$ & $83.30 \mathrm{~b}$ & $84.40 \mathrm{~b}$ & $100.00 \mathrm{a}$ \\
\hline Pepper & $66.63 \mathrm{ab}$ & $59.97 \mathrm{~b}$ & $85.53 \mathrm{a}$ & $53.30 \mathrm{~b}$ & $62.10 \mathrm{~b}$ & $68.87 \mathrm{ab}$ \\
\hline Eggplant & $73.30 \mathrm{ab}$ & $78.83 \mathrm{ab}$ & $87.77 \mathrm{a}$ & $67.77 \mathrm{~b}$ & $81.07 \mathrm{ab}$ & $77.73 \mathrm{ab}$ \\
\hline
\end{tabular}

\subsection{Germination speed (days)}

The germination speed of seed of tomato, pepper, and eggplant was importantly affected by different types of growing medium. The longest number of days required for germination (7.00 days) was determined for tomato seeds sowed in the growing medium 1 (soil + sand + organic manure 1:1:1) and growing medium 5 (soil + sheep manure 1:1) whereas the fewest number of days (5.00 days) was required for seeds sowed in the growing medium 3 (peat moss) and the growing medium 6 (peat moss + compost 1:1).

In term of germination speed of pepper seeds, the highest number of days needed for germination (19.00 days) was due to germination in the growing medium 2 (compost) while the lowest number of days (11.00) for seed to germinate was observed in the pods containing the growing medium 3 (peat moss) in comparison with other growing media. In case of germination speed for eggplant seeds, the peak number of days (11.00 days) for germination was needed for seeds sowed in growing medium 1 (soil + sand + organic manure 1:1:1) and the fewest number of days (8.00 days) for eggplant seeds to germinate was owed to the growing medium 3 and the growing medium 6 as seen in Table 4 .

Table 4 Effect of different growing mediums and biofertilizer on germination speed (day) of tomato, pepper and eggplant seedlings

\begin{tabular}{|l|c|c|c|c|c|c|}
\hline \multirow{2}{*}{ Species } & \multicolumn{6}{|c|}{ Media } \\
\cline { 2 - 7 } & M1 & M2 & M3 & M4 & M5 & M6 \\
\hline Tomato & $7.00 \mathrm{a}$ & $6.00 \mathrm{~b}$ & $5.00 \mathrm{c}$ & $6.00 \mathrm{~b}$ & $7.00 \mathrm{a}$ & $5.00 \mathrm{c}$ \\
\hline Pepper & $17.00 \mathrm{~b}$ & $19.00 \mathrm{a}$ & $11.00 \mathrm{e}$ & $15.00 \mathrm{c}$ & $15.00 \mathrm{c}$ & $14.00 \mathrm{~d}$ \\
\hline Eggplant & $11.00 \mathrm{a}$ & $9.00 \mathrm{c}$ & $8.00 \mathrm{~d}$ & $9.00 \mathrm{c}$ & $10.00 \mathrm{~b}$ & $8.00 \mathrm{~d}$ \\
\hline
\end{tabular}




\subsection{Vegetative growth parameters}

\subsubsection{Length of stem}

Growing medium, biofertilizer and their interaction significantly affected the stem length (Figure 1). When the effect of the medium on the stem length were examined, it was seen that the longest stems in all three species were obtained from plants grown in media 3. The shortest seedlings in tomato and eggplant were obtained from medium 1 but in pepper the shortest seedlings were obtained from medium 2 and medium 4 . In all species biofertilizer application improved the length of stem.

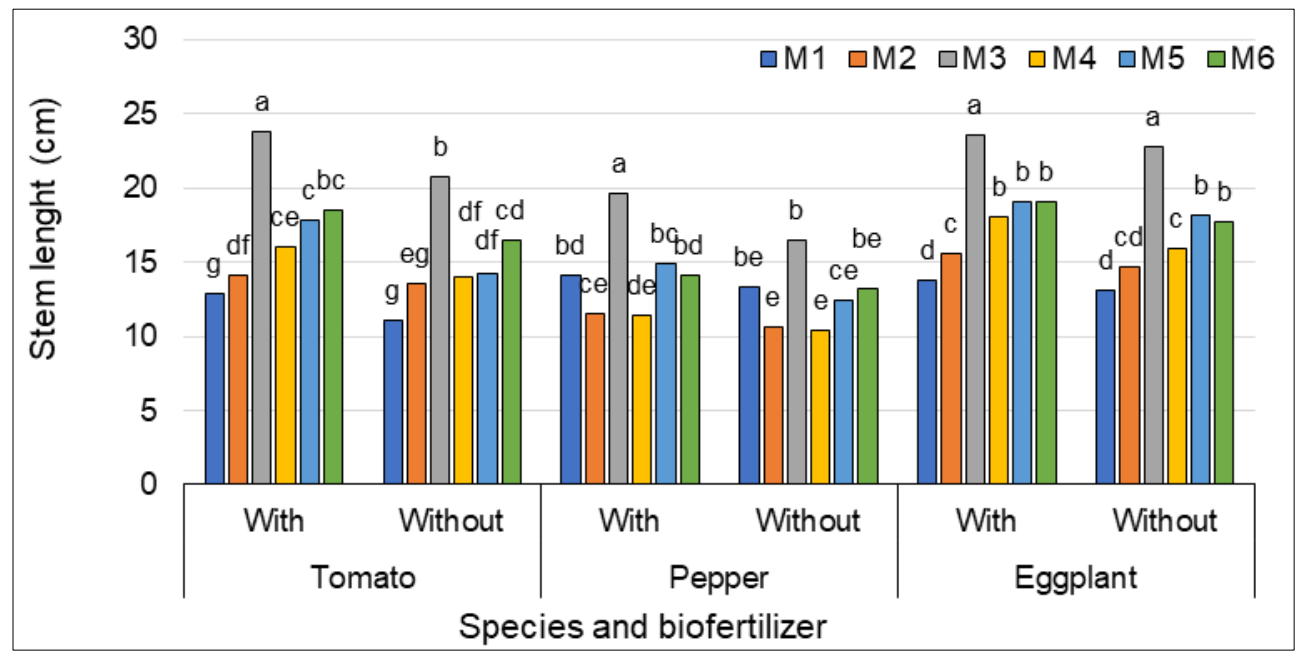

Figure 1 Effect of different growing mediums and biofertilizer on stem length $(\mathrm{cm})$ of tomato, pepper and eggplant seedlings

\subsection{Stem diameter $(\mathrm{mm})$}

The stem diameter of Solanaceae seedlings was statistically significantly affected due to the use of different growing mediums. The growing medium 3 (peat moss) had the highest average stem diameters $6.36 \mathrm{~mm}, 4.58 \mathrm{~mm}, 5.38 \mathrm{~mm}$ for tomato, pepper, and eggplant seedlings, respectively exceeding other five growing media.

Although the biofertilizer did not significantly affect the stem diameter, it resulted in a higher average stem diameter than the control (without treatment) for all species.

Dual interaction between the growing medium and the biofertilizer caused a significant effect on stem diameter of all seedlings as clarified in the Figure 2. The thickest stem diameter was measured from seedlings with and without biofertilizer in medium 3 (peat moss) in all of three crops.

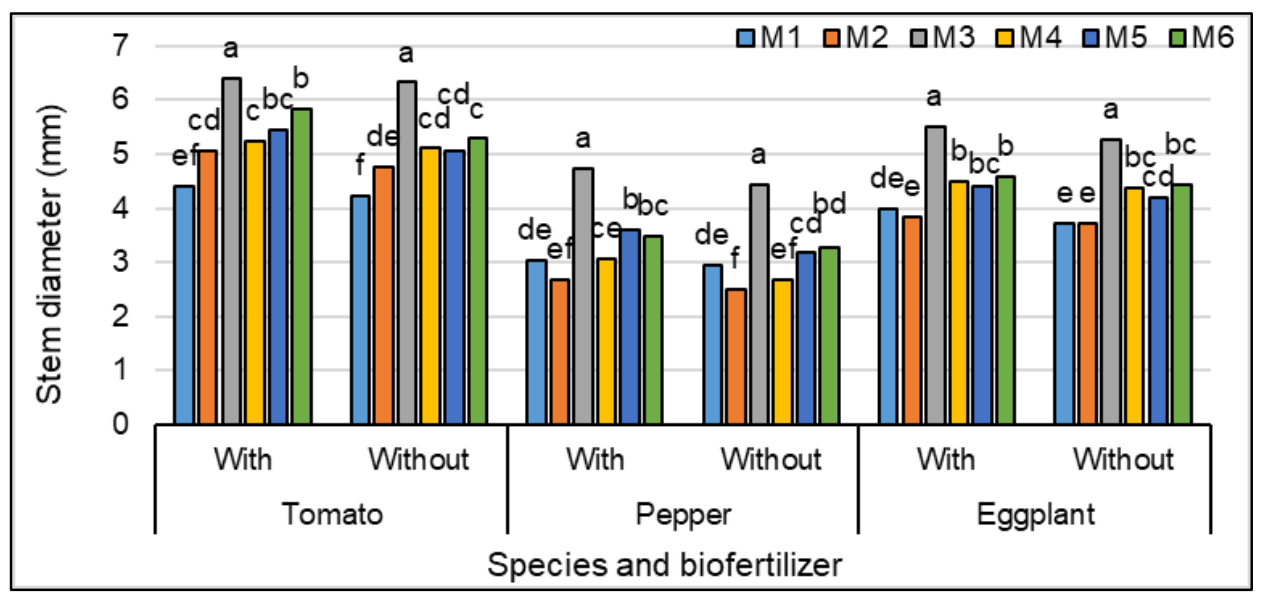

Figure 2 Effect of different growing mediums and biofertilizer on stem diameter ( $\mathrm{mm}$ ) of tomato, pepper and eggplant seedlings 


\subsection{Number of leaves}

Results in the Figure 3 showed significant differences in the number of leaves for Solanaceae seedlings attributing to the root inoculation with biofertilizer and raising in different growing mediums. In all three species, the highest number of leaves was obtained from seedlings grown in M3 medium. In addition, in all three species, the highest number of leaves was determined in the seedlings inoculated with biofertilizer. The biofertilizer inoculation led to the production of the higher number of leaves over control. The interaction between growing medium and biofertilizer significantly affected number of leaves of tomato, pepper, and eggplant seedlings. For tomato and eggplant seedlings, the highest leaf number was obtained from seedlings with and without biofertilizer application in M3 medium, while the highest leaf number in pepper was obtained from seedlings with biofertilizer application in M3 medium. The lowest number of leaves of tomato was determined in seedlings with and without biofertilizer in M1 medium. Pepper had lowest leaf numbers in M2 and M4 medium and without biofertilizer. The lowest leaf number in eggplant was counted from seedlings without biofertilizer in M2, M5 and M6 mediums.

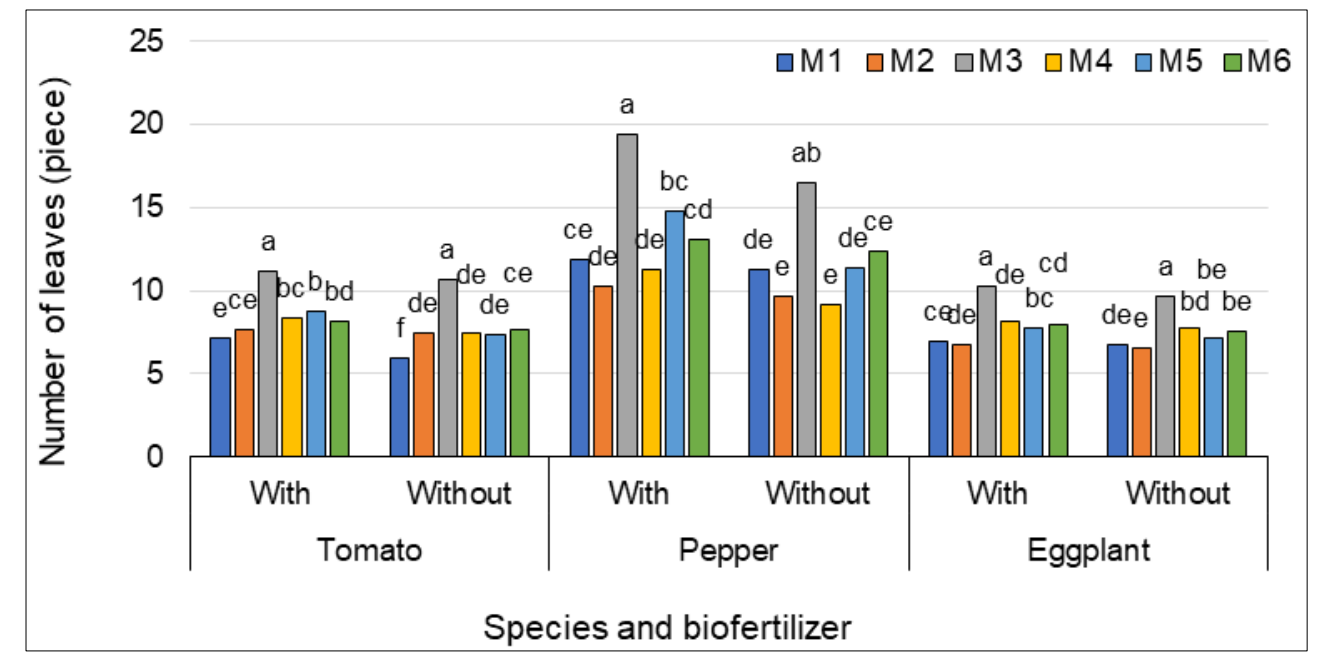

Figure 3 Effect of different growing mediums and biofertilizer on number of leaves. Plant-1 of tomato, pepper and eggplant seedlings

\subsection{Chlorophyll (\%)}

The use of different growing mediums, root inoculation with biofertilizer and interaction between growing medium and biofertilizer caused an important effect on chlorophyll index of Solanaceae seedlings. For all species, seedlings grown in growing medium 3 (peat moss) had the highest chlorophyll index when compared to other mediums. Also, inoculation with biofertilizer in all three species increased the chlorophyll index compared to the control.

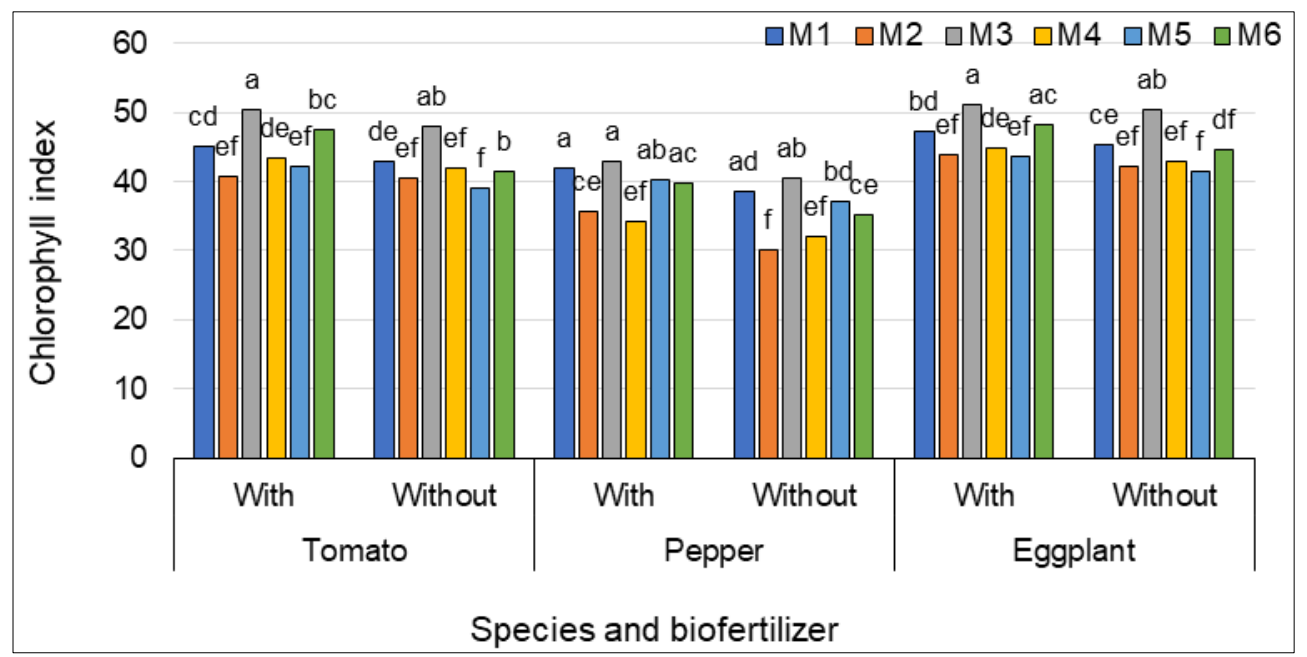

Figure 4 Effect of different growing mediums and biofertilizer on chlorophyll (\%) of tomato, pepper and eggplant seedlings 
The dual interaction between the growing medium and the biofertilizer had a significant impact on the chlorophyll index of seedlings of the three crops, as shown in Figure 4. The maximum chlorophyll index for tomato and eggplant was measured in seedlings with and without biofertilizer inoculation in medium 3 (peat moss). The highest chlorophyll index in pepper was obtained from seedlings inoculated with biofertilizer in medium 1 (soil:sand:sheep manure 1:1:1) and medium 3. The lowest chlorophyll index was measured in seedlings non-inoculated with biofertilizer grown in medium 5 for tomato and eggplant, but in pepper the lowest chlorophyll index was measured in seedlings noninoculated with biofertilizer grown in medium 2.

\subsection{Fresh weight of shoot (g)}

The effect of various growing media, root inoculation of biofertilizer and the interaction between them on the fresh weight of the shoot was found to be significant as seen in Figure 5.

For fresh shoot weight of tomato, pepper and eggplant seedlings, the best growing medium was peat moss, which provided a heavier fresh shoot weight than other growing media. The inoculation of biofertilizer increased the shoot fresh weight as compared to control for all species. The seedlings inoculated with biofertilizer in medium 3 produced the heaviest fresh weight of shoot in tomato and pepper. But in eggplants, the highest fresh weight of shoot was obtained from seedlings inoculated and non-inoculated with biofertilizer in medium 3.

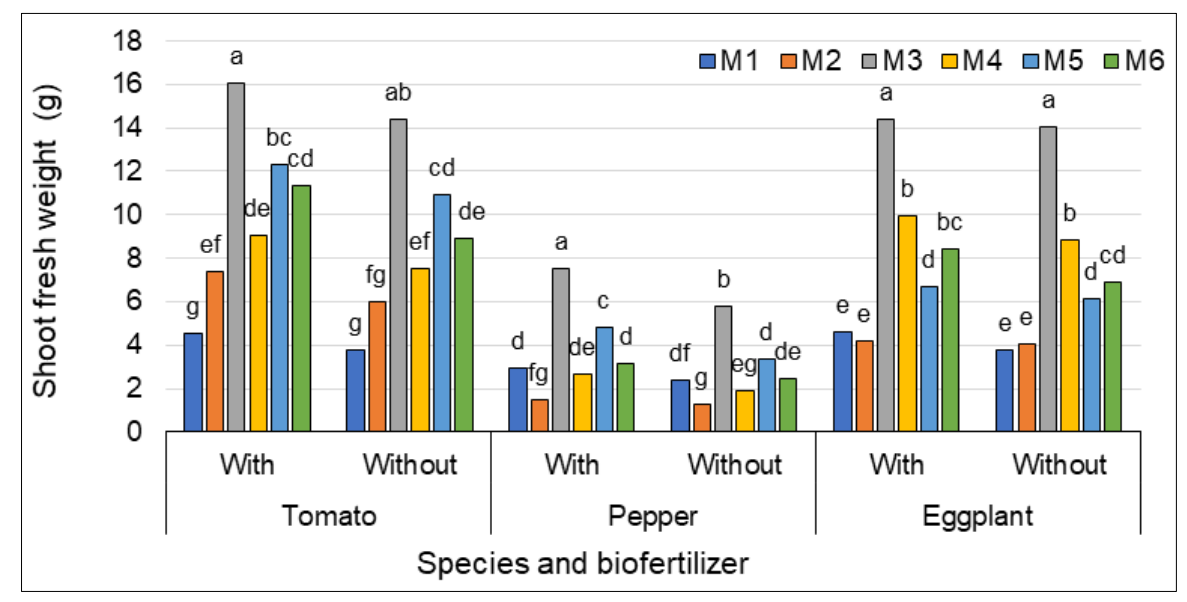

Figure 5 Effect of different growing mediums and biofertilizer on fresh weight of shoot (g) of tomato, pepper and eggplant seedlings

\subsection{Fresh weight of roots $(\mathrm{g})$}

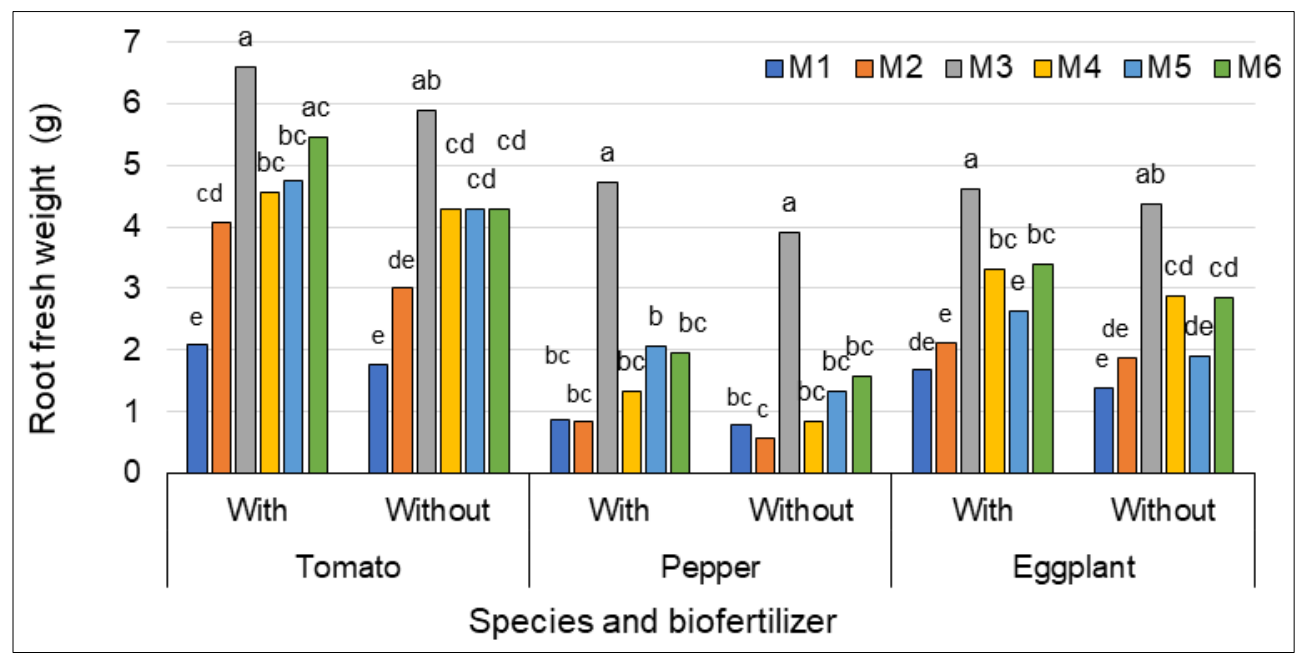

Figure 6 Effect of different growing mediums and biofertilizer on fresh weight of roots (g) of tomato, pepper and eggplant seedlings 
As seen in the Figure 6, the growing medium markedly affected the fresh weight of the roots for the three crop seedlings. The highest fresh root weights were measured from seedling of tomato, pepper, and eggplant grown in the growing medium 3 (Peat moss). Biofertilizer application improved fresh root weight in all species, but only tomato had statistical significance. The heaviest roots were obtained from seedlings inoculated with biofertilizer and grown in medium 3 for all species.

\subsection{Mineral content in leaves}

\subsubsection{Nitrogen percentage (\%)}

The data in Figure 7 revealed that growing mediums and root inoculation with the biofertilizer along with their interactions had significant effect on nitrogen percentage. The highest nitrogen content in tomato, pepper and eggplant was recorded from seedlings grown on medium 1, medium 2 and medium 6, respectively. The biofertilizer inoculation increased the nitrogen content in leaves of tomato, pepper and eggplant seedlings compared to the control. The highest nitrogen content was in seedlings inoculated with biofertilizer for tomato in medium 1 and for pepper in medium 2 . However, the highest nitrogen content in eggplant was obtained from seedling non-inoculated with biofertilizer grown in medium 6.

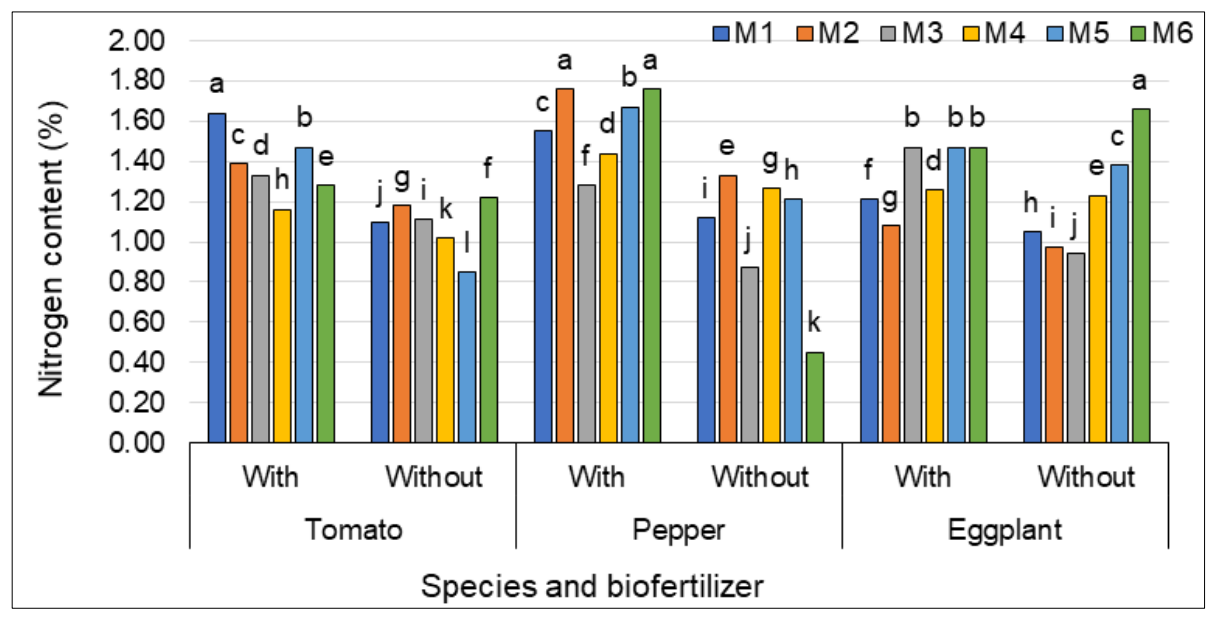

Figure 7 Effect of different growing mediums and biofertilizer on nitrogen content (\%) of tomato, pepper and eggplant seedlings

\subsection{Phosphorus content (\%)}

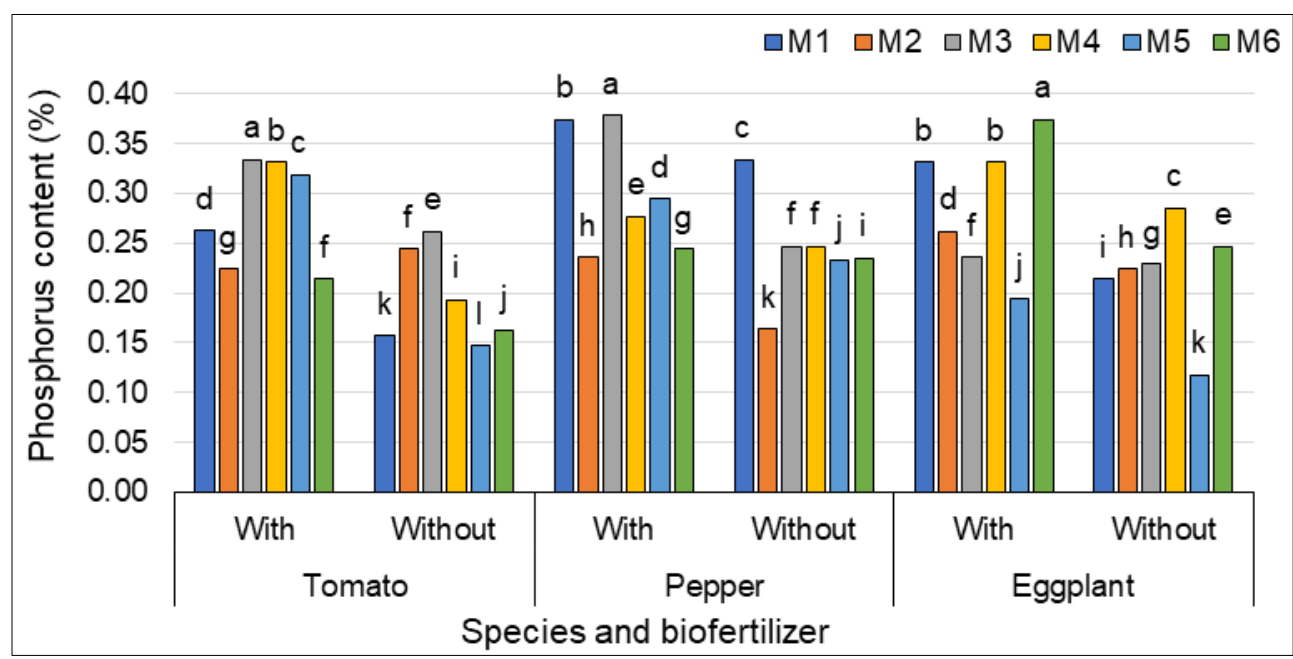

Figure 8 Effect of different growing mediums and biofertilizer on phosphorus content (\%) of tomato, pepper and eggplant seedlings 
The phosphorus content of tomato, pepper, and eggplant seedlings was significantly affected with the use of the growing medium, the biofertilizer and their combination (Figure 8). The highest phosphorus content in leaves of tomato, pepper and eggplant was determined in seedlings in the growing medium 3 (peat moss), M1 (soil + sand + sheep manure1:1:1) and M6 (peat moss + compost 1:1), respectively. The biofertilizer application increased phosphorus content in the leaves of all the species in the trial. In tomato and pepper, the highest phosphorus content was obtained from seedlings inoculated with biofertilizer and grown on medium 3, while in eggplants it was obtained from seedlings inoculated with biofertilizer and grown on medium 6.

\subsection{Potassium percentage (\%)}

As presented in the Figure 9, potassium content of species showed important differences based on growing medium and biofertilizer application. Medium 6 had highest potassium content in leaves of tomato, medium 1 had highest potassium content in leaves of pepper and eggplant seedlings. The biofertilizer application increased potassium content of seedlings in all species. In tomato, the highest potassium content was obtained from seedlings grown in medium 6 and inoculated with biofertilizer, while in pepper and eggplant it was obtained from seedlings grown in medium 1 and inoculated biofertilizer.

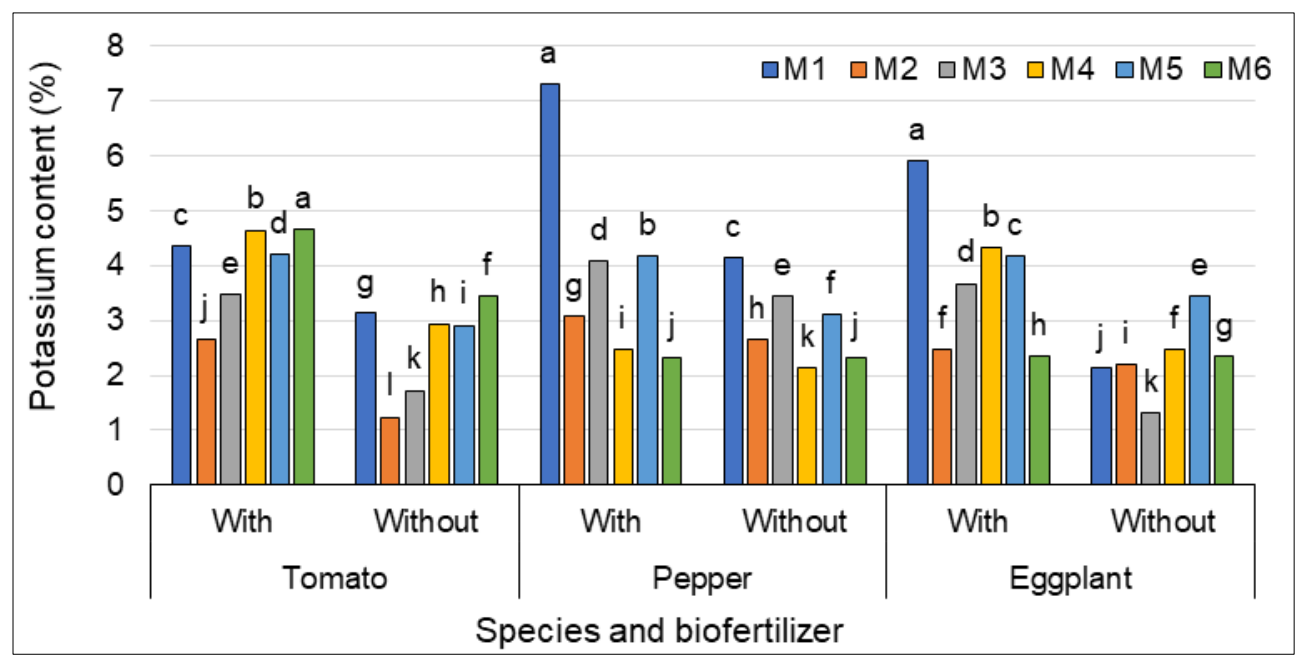

Figure 9 Effect of different growing mediums and biofertilizer on potassium content (\%) of tomato, pepper and eggplant seedlings

\section{Discussion}

Organic production of seedlings for horticultural crops is the key factor in the adoption of a successful organic farming since obtaining of a high yield with a good quality is bonded with raising of healthy seedlings with high quality. This can be achieved by utilization of natural and safe substances that do not harm the public health and the environment. But every medium has different physical and chemical properties. The seeds germination, development, and functional rooting system directly is affected of growing media or substrates [29]. For this reason, it is important to know the effects of these mediums or their mixtures on seedling growth. Our results revealed that the growing medium consist of medium 3 (peat moss) caused a remarkable increase in germination rate (\%) of Solanaceae seeds (tomato, pepper, and eggplant) as compared to other growing mediums. The similar findings were reported by Melo et al. [11] who displayed that the peat moss-based growing medium led to a marked increase in the rate of seed germination of tomato. Peat is an organic medium used alone or mixed with other growing mediums in commercial seedling production. The improvement in the germination rate of Solanaceae seeds can be explained by the fact that peat moss provides the water and oxygen required for germination in appropriate proportions. Peat moss substrates have perfect physical properties such as maximum porosity and good water holding capacity, slow decomposition rate, lower bulk density. Furthermore, it has excellent chemical properties including potential cation exchange capacity (CEC) and efficient nutrient content leading to creation of optimal conditions for seed germination and rapid seedling emergence [30].

The peat moss medium and root inoculation with biofertilizer importantly improved vegetative growth of tomato, pepper and eggplant seedlings in term of stem length, stem diameter, number of leaves, chlorophyll index, fresh weight of shoot and fresh weight of roots. A good substrate supplies sufficient support or anchors to the plant, storage for nutrients and water, oxygen for the roots, and gas exchange between the root medium and the atmosphere [31]. The 
peat is considered as the favourable component for organic substrates utilized for growing of a huge number of vegetables seedling and ornamental plants. Moreover, peat is a commercial material containing considerable concentrations of nourishing elements which enhanced the soil fertility and made the nutrients to be more obtainable for plant leading to better plant outgrowth, yield and mineral content [32,33]. Unal [12] showed in a field trial that the vegetative growth and quality of tomato seedlings was importantly enhanced by usage of peat. Similarly, Keefe et al. [34] indicated that the peat moss substrate significantly improved vegetative traits of Chinese cabbage like plant height, plant weight, leaf number per plant and stem diameter. The good root growth of seedlings may ascribe to the physical, chemical and biological features with moderate content of nutrient elements and low $\mathrm{pH}$. It also has a good capacity to hold water, proper aeration and drainage, low weight and devoid of pests and diseases making it the preferred medium for providing a suitable environment for root growth and proliferation [35, 36, 37]. The results agree with that displayed by Tuzel et al. [14] who measured an increased root growth components of tomato seedlings. Another reason for the higher vegetative development in the peat medium may be the earlier germination and earlier development of the seeds sowed in the peat medium. Also, peat moss had the lowest EC value compared to the other mediums. Therefore, plant developed better than the others.

The biofertilizer made a notable improvement in vegetative and root growth parameter of all seedlings. This increase can be attributed to the presence of beneficial microorganisms and humic acid in the biofertilizer. Biofertilizers are natural fertilizers that are ecofriendly, cost effective and sustainable source of necessary nutrients required for plant outgrowth and development [38].

These microorganisms give essential macro and micronutrients through various processes such as fixation of nitrogen, dissolution of phosphate and potassium or mineralization. Also they trigger of important plant growth stimulating hormones [39, 40]. Almammory and Matloob [41] showed that Tichoderma harzianum and effective microorganisms (EM1) caused a significant amelioration in the vegetative traits of eggplant. On the other hand, Nurlila et al. [20] recorded a significant increase in the vegetative and root growth of tomato with the application of biofertilizer.

The leaf mineral content of seedlings like nitrogen $(\mathrm{N})$, phosphorus $(\mathrm{P})$, and potassium $(\mathrm{K})$ was significantly changed with the growing medium type and the root inoculation with biofertilizer. The highest nitrogen, phosphorus and potassium contents were obtained from medium 1, medium 3 and medium 6 in tomato, medium 2 and 6, medium 3 and medium 1 in pepper, and medium 6, medium 6 and medium 1 in eggplant, respectively. Awad [15] reported that the compost-based growing media mixtures remarkably elevated mineral content of organic tomato seedlings. El-Sayed et al. [16] measured an improved mineral content (N, $\mathrm{P}$, and $\mathrm{K})$ in leaves of strawberry grown in perlite: peat-moss (1:1 $V / V$ ) M1. Chepkoech [42] recorded a high content of N, P, and K in the leaves of Kale crop due to the application of organic manures. The composition of animal manures changes with the effect of many factors such as the type of the animal, age of animal, nutritional status, storage conditions of manure and duration [43].

\section{Conclusion}

The use of seedlings in vegetable production not only provides earliness, but also increases profitability by saving seeds, energy and field. The medium to be used in production should be cheap and easy to obtain. In addition, the recycling of organic wastes into production forms the basis of a sustainable production. According to our results, seedling growth was affected by growing mediums and biofertilizer application. In general, the quality of seedlings grown in peat medium was markedly better than other mediums. In addition to, biofertilizer applications have made a significant contribution to seedling growth in all mediums and in all species. For this reason, it is recommended to use peat medium in seedling production and to apply biofertilizers. However, when peat is limited, peat use can be reduced by mixing peat and compost in a 1:1 ratio.

\section{Compliance with ethical standards}

\section{Acknowledgments}

The authors thank to the General Directorate of Agriculture of the City of Zakho, Duhok Governorate for their helps.

\section{Disclosure of conflict of interest}

The authors declare no conflict of interest. 


\section{References}

[1] Aksoy U. Ecological agriculture: An Overview, Turkey 2Ecological Agriculture Symposium. 2001; 14-16.

[2] Kurtar ES, Ayan AK. Organic farming and condition. J. of the Fac. of Agric. OMÜ Turkey. 2004; 19 : 56-64.

[3] Zengin M. Organic agriculture. Istanbul, Turkey: Hasad Publish. 2007.

[4] Hammad HM, Khaliq A, Ahmad A, Aslam M, Malik AH, Farhad W. Influence of different organic manures on wheat productivity. Int. J. Agric. Biol. 2011; 13: 137-140.

[5] Zaccheo PVC, Aguiar RS, Stenzel NMC, Neves CSVJ. Tamanho de recipientes e tempo de formacao de mudas no desenvolvimento e producao de maracujazeiro- amarelo. Rev. Bras. Frutic. 2013; 35(2): 603-607.

[6] Kubato C, Balliu A, Nicola S. Quality of Planting Materials. Good Africultural Practices for Greenhouse Vegetable Crops: Principles for Mediterranean climate Areas. FAO Plant Production and Protection Paper. 2013; 217: 355378.

[7] Grunert 0, Perneel M, Vandaele S. 'Peat-based organic growbags as a solution to the mineral wool waste problem.' Mires and Peat. 2008; 3: 1-5.

[8] Douglass FJ, Thomas DL, Tara L. Nursery manual for native plants. A guide for tribal nurseries. Nursery Management. 2009; 1: 77-93.

[9] Vaughn SF, Deppe NA, Palmquist DE, Berhow MA. 'Extracted sweet corn tassels as a renewable alternative to peat in greenhouse substrates.' Industrial Crops and Products. 2011; 33: 514-517.

[10] Nair A, Ngouajio M, Biernbaum J. Alfalfa-based organic amendment in peat-compost growing medium for organic tomato transplant production. HortScience. 2011; 46: 253-259.

[11] Melo RAC, Jorge MHA, Bortolin A, Boiteux LS, Oliveira CR, Marconcini JM. Growth of tomato seedlings in substrates containing a nanocomposite hydrogel with calcium montmorillonite (NC-MMt). Research • Hortic. Bras. 2019; 37(2): 199-203.

[12] Unal M. Effect of Organic Media on Growth of Vegetable Seedlings. Pak. J. Agri. Sci. 2013; 50(3): 517-522.

[13] Olaria M, Nebot JF, Molina H, Troncho P, Lapeña L, Llorens E. Effect of different substrates for organic agriculture in seedling development of traditional species of Solanaceae. Spanish Journal of Agricultural Research. 2016; (1): $1-7$.

[14] Tuzel Y, Oztekin GB, Tan E. Use of different growing media and nutrition in organic seedling production. Acta Hortic. 2015; 1107: 165-175.

[15] Awad FA. Effect of different substrates and fertilizers on organic tomato seedlings production. IAMB, Valenzano. Master of science. Mediterranean Organic Agriculture. 2010; 601.

[16] EL-Sayed S, Hassan H, Abul-Soud M, Gad D. Effect of substrate mixtures and nutrient solutions sources on strawberry plants under closed hydroponic system. Journal of Productivity and Development. 2016; 21(1): 97115.

[17] Kawalekar JS. Role of biofertilizers and biopesticides for sustainable agriculture. J. Bio. Innov. $2013 ; 2$ : $73-78$.

[18] Raghuwanshi R. Opportunities and challenges to sustainable agriculture in India. Nebio. 2012; 3: 78-86.

[19] Youssef MMA, Eissa MFM. Biofertilizers and their role in management of plant parasitic nematodes: A review. Journal of Biotechnology and Pharmaceutical Research. 2014; 5(1): 1-6.

[20] Nurlila RU, Bahrun A, Gusti M, Sutariati GAK. Effect of Indigenous Biofertilizer Treatment as Growth Promote on The Vegetative Growth of Tomato. International J. of Scientific and Technology Research. 2020; 9(2): 1015-1018.

[21] Salih Mahdi H, Hussein WA. Effect of Biohealth and Mineral Fertilizer in the Product and Quality of Four Varieties of Eggplant. Euphrates Journal of Agriculture Science. 2017; 9(4): 306-316.

[22] Rueda D, Valencia G, Soria N, Rueda BB, Manjunatha B, Kundapur RR, Selvanayagam M. Effect of Azospirillum spp. and Azotobacter spp. on the growth and yield of strawberry (Fragaria vesca) in hydroponic system under different nitrogen levels. Journal of Applied Pharmaceutical Science. 2016; 6(01): 048-054.

[23] Abou-El-Hassan, S, El-Shinawy MZ. Influence of Compost, Humic Acid and Effective Microorganisms on Organic Production of Red Cabbage. Egypt. J. Hort. 2015; 42(1): 533- 545. 
[24] AOAC. Official Method of Analysis 11th edition Washington D.C. Association of official analysis chemist. 1980; 1015.

[25] Black CA. Methods of Soil Analysis. Part 2. USA: Amer. Soc. of Agron. Inc. 1965.

[26] Matt J. Calorimetric determination of phosphorus in soil and plant material with ascorbic acid. Soil. Sci. 1970; 109: 219-220.

[27] AOAC. Official Method of Analysis 11th edition Washington D.C. Association of official analysis chemist. 1970; 105.

[28] AL-Sahaf FH. Practical Plant Nutrition. Ministry of Higher Education and Scientific Research. Bagdad Univ. Iraq. 1989.

[29] Meena AK, Garhwal OP, Mahawar AK, Singh SP. Effect of different growing media on seedling growth parameters and economics of papaya (Carica papaya L.) cv. Pusa Delicious. Int J Curr Microbiol App Sci. 2017; 6(6): 29642972.

[30] Fascella G. Growing substrates alternative to peat for ornamental plants. Chapter 3. In: Asaduzzaman M, editor. Soilless Culture-Use of Substrates for the Production of Quality Horticultural Crops. Rijeka, Croatia: InTech Open. 2015; 47-67.

[31] Abad M, Noguere P, Puchades R, Maquieira A, Noguera V. Physio-chemical and chemical properties of some coconut dusts for use as a peat substitute for containerized ornamental plants. Bioresource Technology. 2002; 82: 241-245.

[32] Raviv M, Reuveni R, Zion B. Improved medium for organic transplants. Biological Agriculture and Horticulture. 1998; 16: 53-64.

[33] Michel JC. The physical properties of peat: A key factor for modern growing media. Mires and Peat. 2010; 6(02): 1-6.

[34] Keefe DHS, Yoon S, Kwon S, Kwon S, Park J, Kim J, Choi, W, Chung S, Choi W. Growth Performance of Chinese Cabbage using Soilless Cultivation Method. KSIC. 2019; 55-60.

[35] Savvas D, Gianquinto G, Tuzel Y, Gruda N. Good agricultural practices for greenhouse vegetable crops-principles for mediterranean climate areas, 12: soilless culture, in FAO Plant Production and Protection Paper. (Rome: Food and Agriculture Organization of the United Nations). 2013.

[36] Savvas D, Gruda N. Application of soilless culture technologies in the modern greenhouse industry - A review. Eur J Hortic Sci. 2018; 83: 280-293.

[37] Gruda N, Bisbis M, Tanny J. Impacts of protected vegetable cultivation on climate change and adaptation strategies for cleaner production - a review. J Clean Prod. 2019; 225: 324-339.

[38] Raja N. Biopesticides and biofertilizers: ecofriendly sources for sustainable agriculture. Journal of Biofertilizers and Biopesticides. 2013; 04(01): 1-2.

[39] Goel AK, Laura RDS, Pathak DV, Goel A. Use of biofertilizers: potential, constraints and future strategies. International Journal of Tropical Agriculture. 1999; 17: 1-8.

[40] Sinha RK, Valani D, Chauhan K, Agarwal S. Embarking on a second green revolution for sustainable Agriculture by vermiculture biotechnology using earthworms: reviving the dreams of Sir Charles Darwin. Journal of Advanced Biotechnology and Sustainable Development. 2010; 2: 113-28.

[41] Almammory MK, Matloob AA. Efficiency of Trichoderma Harzianum and Biofertilizer Bokashi and Salicyclic acid to Control Fungi Causing Eggplant and Dumping off Disease. Plant Archives. 2019; 19(1): 73-82.

[42] Chepkoech C. Effect of legume integration and application of organic fertilizers on soil nutrient status and kale yield in Kabete, Kenya. [MSc. Thesis]. Kenya: University of Nairobi. 2015.

[43] Erdal İ, Küçükyumuk Z, Şimşek K, Basir M, Baysal GD. Effect of Different Animal Manures on Growth and Mineral Nutrition of Tomato. 1. Uluslararası Tarımsal Yapılar ve Sulama Kongresi Özel Sayısı. 2018; 295-302. 